\title{
Enzymatic Characterization of a Cubilin-Related Serine Proteinase from the Hard Tick Haemaphysalis longicornis
}

\author{
Takeharu MIYOSHI ${ }^{1)}$, Naotoshi TSUJI ${ }^{1) *}$, M. Khyrul ISLAM ${ }^{1)}$, Tsugihiko KAMIO $^{1)}$ and Kozo FUJISAKI ${ }^{2)}$ \\ ${ }^{1)}$ National Institute of Animal Health, National Agricultural Research Organization, 3-1-5 Kannondai, Tsukuba, Ibaraki 305-0856 and \\ ${ }^{2)}$ National Research Center for Protozoan Diseases, Obihiro University of Agriculture and Veterinary Medicine, Inada-cho, Obihiro, \\ Hokkaido 080-8555, Japan
}

(Received 6 April 2004/Accepted 13 May 2004)

\begin{abstract}
In the present study, we performed enzymatic characterization of Haemaphysalis longicornis serine proteinase (HISP) with a view to shed light on the mechanisms of blood digestion in the hard ticks. Escherichia coli-expressed recombinant HISP (rHISP) was shown to potently hydrolyze the synthetic substrates Bz-(DL)-Arg- $p$ NA, Z-Ala-Ala-Leu- $p$ NA and Suc-Ala-Ala-Ala- $p$ NA and yielded an activity of $31.5,88.2$ and $18.3 \mu \mathrm{mol} / \mathrm{min} / \mathrm{mg}$ protein, respectively at an optimum temperature of $25^{\circ} \mathrm{C}$. However, the enzyme showed little activity to hydrolyze the substratese Suc-Arg-Pro-Phe-His-Leu-Leu-Val-Tyr-MCA and Pyr-Phe-LeupNA. The optimum pH for the enzyme was shown to be 4.0 to 5.0. Several inhibitors such as antipain, leupeptin and phenylmethylsulfonyl fluoride (PMSF), specific for serine proteinase were shown to inhibit enzyme activity by $20-82 \%$, while E-64 (specific for cysteine proteinases) and pepstatinA (specific for aspartic proteinases) had shown only little inhibitory effects on it. This is the first report on enzymatic characterization of a functional serine proteinase from the hard ticks.
\end{abstract}

KEY WORDS: enzyme activity, Haemaphysalis longicornis, serine proteinase.

J. Vet. Med. Sci. 66(10): 1195-1198, 2004

Ticks and tick-borne diseases are of extreme importance throughout the world and the associated economic losses are immense. Reliance on acaricides for tick control has led to serious problems which include development of resistance to acaricides that created control problems [5], and increased the threat to the wide-spread occurrence of the pathogens associated with ticks. In addition, chemical residues in animal products, and the effects of such chemicals on the environment, must be considered when new acaricides are developed.

Proteolytic enzymes may represent interesting target molecules for drug design because of its involvement in the mediation of a wide range of cellular processes such as protein metabolism and the processing of precursor proteins in the living organisms [11]. In haematophagous ticks, blood digestion in the midgut is thought to be the most essential process because it is the source of energy as well as the most critical interface between the ticks and the pathogens that transmitted by ticks. Studies have reported that aspartic and cysteine proteinases exert proteolytic role, in the midguts [8, 13] of the hard tick Boophilus microplus.

The hard tick Haemaphysalis longicornis is distributed in a vast area of Eurasia, including Japan [6], where it transmits a wide range of pathogens, including viruses, rickettsia and protozoan parasites, causing important human and animal diseases [17]. In particular, $H$. longicornis serves as a vector of Theileria orientalis, which is the most economically important protozoan infectious disease of cattle in Asia [6]. In contrast to the extensive reports on proteinase activ-

\footnotetext{
* Correspondence to: Tsuji, N., Laboratory of Parasitic Diseases, National Institute of Animal Health, National Agricultural Research Organization, 3-1-5 Kannondai, Tsukuba, Ibaraki 305-0856, Japan.
}

ities in haematophagous insects, very little is known about these activities in the hard tick $H$. longicornis despite of its high vector potentiality.

Recently, we cloned and partially characterized a gene that encodes a functional serine proteinase from the hard tick H. longicornis [9]. The H. longicornis serine proteinase (HISP, Genbank accession number: AB 127388) with a signal sequence was composed of complement $\mathrm{C} 1 \mathrm{r} / \mathrm{C} 1 \mathrm{~s}$, Uegf, and bone morphogenic protein-1 (CUB) domain, low-density lipoprotein receptor class A (LDL) domain and catalytic domain and has a molecular mass of $50 \mathrm{kDa}$ and a $\mathrm{pI}$ of 8.2. The endogenous form of the enzyme was intensely localized in the midgut epithelial cells of the tick and demonstrated to be up-regulated during blood feeding. In this study, we determined substrate specificity and temperature/ $\mathrm{pH}$ dependent activity of recombinant HISP (rHlSP). The serine proteinases are one of the largest multigene proteolytic families found in a wide range of tissues and have well characterized roles in diverse cellular activities in mammals. The present study was, therefore, undertaken to elucidate the enzymatic functions of serine proteinases in the hard ticks to increase our understanding on the biology of the blood digestion.

\section{MATERIALS AND METHODS}

Preparation of recombinant $H$. longicornis serine proteinase: Expression and purification of rHISP was carried out as previously described [18]. Briefly, the coding region of catalytic domain of the HISP gene was inserted into the pTrcHis B plasmid (Invitrogen, CA., U.S.A.) and transformed into E. coli (Top10F', Invitrogen) following standard techniques. rHISP was purified by HPLC using metal chelation chromatography (Invitrogen) under denaturing 
conditions as described in the manufacturer's protocol. Protein eluted with imidazole was concentrated by using Centrisart (molecular weight cut off, 20,000; Sartorius, Goettingen, Germany) and then dialyzed extensively against $20 \mathrm{mM}$ Tris- $\mathrm{HCl}, \mathrm{pH} 7.5$ and $250 \mathrm{mM} \mathrm{NaCl}$ in a slide-A Lyzer dialysis cassette (Pierce, Rockford, U.S.A.). The purification process was monitored by SDS-PAGE. Protein concentration was determined by Micro BSA reagent (Pierce).

Enzyme assay: Enzyme assay was performed as previously described [9]. Briefly, substrate specificity assays with the rHISP were performed in a standard reaction mixture containing $25 \mathrm{mM}$ citric acid/50 $\mathrm{mM}$ sodium phosphate $\mathrm{pH} 5.0,5 \mathrm{mM}$ dithiothreitol and $200 \mu \mathrm{M}$ of chromogenic or fluorogenic substrates. The reaction was started by adding $2.5 \mu \mathrm{g}$ of rHISP into the reaction mixture. Enzyme (specific) activity was defined as $\mu \mathrm{mol}$ of $p$-nitroanilin ( $p \mathrm{NA}$ ) or 7-amino-4-methyl-coumarin (AMC) released by the hydrolysis of each substrate per min per mg of protein. The hydrolysis of Bz-L-Arg- $p$ NA, Z-Ala-Ala-Leu- $p$ NA, SucAla-Ala-Ala- $p$ NA, uc-Arg-Pro-Phe-His-Leu-Leu-Val-TyrMCA and Pyr-Phe-Leu- $p$ NA was determined. All of these synthetic substrates were purchased from Peptide Institute (Osaka, Japan). Chromogenic assays were monitored by SPECTRAFLUOR (TECAN, Maennedorf, Switzerland) at $405 \mathrm{~nm}$ absorption. Fluorogenic assays were monitored with the wavelength pair of 360-465 nm for emission and excitation, respectively. To determine $\mathrm{pH}$ dependent $\mathrm{rHISP}$ activity, we used $25 \mathrm{mM}$ citric acid $/ 50 \mathrm{mM}$ sodium phosphate buffer in the $\mathrm{pH}$ range of $3-8$ at $25^{\circ} \mathrm{C}$. Temperature dependency of the enzyme was determined by incubating the recombinant protein for $5 \mathrm{~min}$ in a standard reaction mixture $[20 \mathrm{mM}$ citric acid/sodium phosphate, $\mathrm{pH} 5.0,5$ $\mathrm{mM}$ dithiothreitol and $200 \mu \mathrm{M}$ of substrates in a total volume] at various temperatures $\left(15,25,35\right.$ and $\left.45^{\circ} \mathrm{C}\right)$.

Enzyme inhibition studies: To determine the sensitivity of rH1SP to inhibition by several known proteinase inhibitors, we examined E-64, antipain, leupeptin and pepstatin A at micromolar range, and PMSF at milimolar range. All inhibitors purchased from Sigma (MO., U.S.A.). The inhibitory effects were calculated by measuring residual enzyme activity upon $500 \mu \mathrm{M} \mathrm{Bz-L-Arg-pNA}$ after the recombinant enzyme preincubated for $15 \mathrm{~min}$ in the presence of inhibitors mentioned above.

\section{RESULTS}

Enzymatic activity of rHlSP: We revealed that rHISP potently hydrolyzed the substrates Bz-(DL)-Arg- $p$ NA and Z-Ala-Ala-Leu- $p$ NA specific for serine proteinase and yielded a maximum activity of $31.5 \mu \mathrm{mol} / \mathrm{min} / \mathrm{mg}$ protein and $88.2 \mu \mathrm{mol} / \mathrm{min} / \mathrm{mg}$ protein, respectively (Table 1). However, the enzyme showed a relatively lower hydrolyzing efficiency on the substrate Suc-Ala-Ala- $p$ NA with a recorded activity of $18.3 \mu \mathrm{mol} / \mathrm{min} / \mathrm{mg}$ protein (Table 1 ). We also achieved a little activity of the enzyme using the substrates Suc-Arg-Pro-Phe-His-Leu-Leu-Val-Tyr-MCA
Table 1. Hydrolyzing activity of chromogenic substrates by rHl$\mathrm{SP}^{\mathrm{a})}$

\begin{tabular}{|c|c|}
\hline Activity $(\mu \mathrm{m}$ & hol/min/mg protein) \\
\hline $\begin{array}{l}\text { Bz-(DL)-Arg- } p \text { NA } \\
\text { (substrate for trypsin) }\end{array}$ & 31.5 \\
\hline $\begin{array}{l}\text { Z-Ala-Ala-Leu- } p \text { NA } \\
\text { (substrate for subtilisin A) }\end{array}$ & 88.2 \\
\hline $\begin{array}{l}\text { Suc-Ala-Ala-Ala- } p \text { NA } \\
\text { (substrate for elastase) }\end{array}$ & 18.3 \\
\hline $\begin{array}{l}\text { Suc-Arg-Pro-Phe-His-Leu-Leu-Val-Tyr-MCA } \\
\text { (substrate for renin) }\end{array}$ & 0.15 \\
\hline $\begin{array}{l}\text { Pyr-Phe-Leu- } p \text { NA } \\
\text { (substrate for thiol proteinase) }\end{array}$ & 0.36 \\
\hline \multicolumn{2}{|c|}{$\begin{array}{l}\text { Diluted rHISP protein }(2.5 \mu \mathrm{g}) \text { was assayed in the standard reaction } \\
\text { mixture containing } 25 \mathrm{mM} \text { citric acid / sodium phosphate, } \mathrm{pH} 5.0,5 \\
\mathrm{mM} \text { DTT, } 0.4 \mathrm{mM} \text { substrate in a final volume of } 50 \mu l \text {. The } \\
\text { hydrolytic activity of the enzyme was monitored by the } \\
\text { spectrophotometer at } 405 \mathrm{~nm} \text { of wavelength for absorbance. }\end{array}$} \\
\hline
\end{tabular}

and Pyr-Phe-Leu- $p$ NA. To determine the $\mathrm{pH}$ and temperature dependence activity of rHISP, we used highly typical substrates for serine proteinases, Bz-L-Arg- $p$ NA, Z-AlaAla-Leu- $p$ NA and Suc-Ala-Ala-Ala- $p$ NA. The recombinant enzyme exhibited its activity over a wide $\mathrm{pH}$ range $\mathrm{pH}$ 3 to 8 ) on these substrates. The optimum activity of rHISP was, however, achieved at $\mathrm{pH} 4$ with the substrate Bz-LArg- $p$ NA and Z-Ala-Ala-Leu- $p \mathrm{NA}$, and at $\mathrm{pH} 5$ with SucAla-Ala-Ala- $p$ NA (Fig. 1A). Interestingly, the recombinant enzyme also showed its activity over a broad range of temperature $\left(15\right.$ to $45^{\circ} \mathrm{C}$ ) (Fig. 1B) and the highest activity was recorded at a temperature of $25^{\circ} \mathrm{C}$ for these synthetic substrates. These results suggested that serine proteinase in the hard ticks may retain its activity well even the environmental temperature goes under a drastic change as usually occurs in experience summer or in winter months.

Inhibition of rHlSP activity: Several well characterized proteinase inhibitors were tested to inhibit the activity of rHISP by using the substrates Bz-L-Arg- $p$ NA, Z-Ala-AlaLeu- $p$ NA and Suc-Ala-Ala-Ala- $p$ NA. The activity of rHISP was most efficiently inhibited by $82 \%$ by antipain at a concentration of $5 \mu \mathrm{M}$. rHISP activity was also found to be inhibited over a range of 43 to $75 \%$ by leupeptin and PMSF, which were well known serine proteinase inhibitors (Table $2)$. By contrast, very little or no inhibitory effect (0-5\%) was exerted by the inhibitors E-64 and pepstatin A in this study. The sensitivity of specificity of rHISP to the well known inhibitors used in the present study indicates that recombinant enzyme conserves its enzymatic features of serine proteinases reported from a diverse source of organisms.

\section{DISCUSSION}

Serine proteinases with diverse cellular activities have been reported from a wide range of organisms including mammals, prokaryotes and arthropods [7, 10, 11] as well. Trypsins and chymotrypsins are the most extensively stud- 

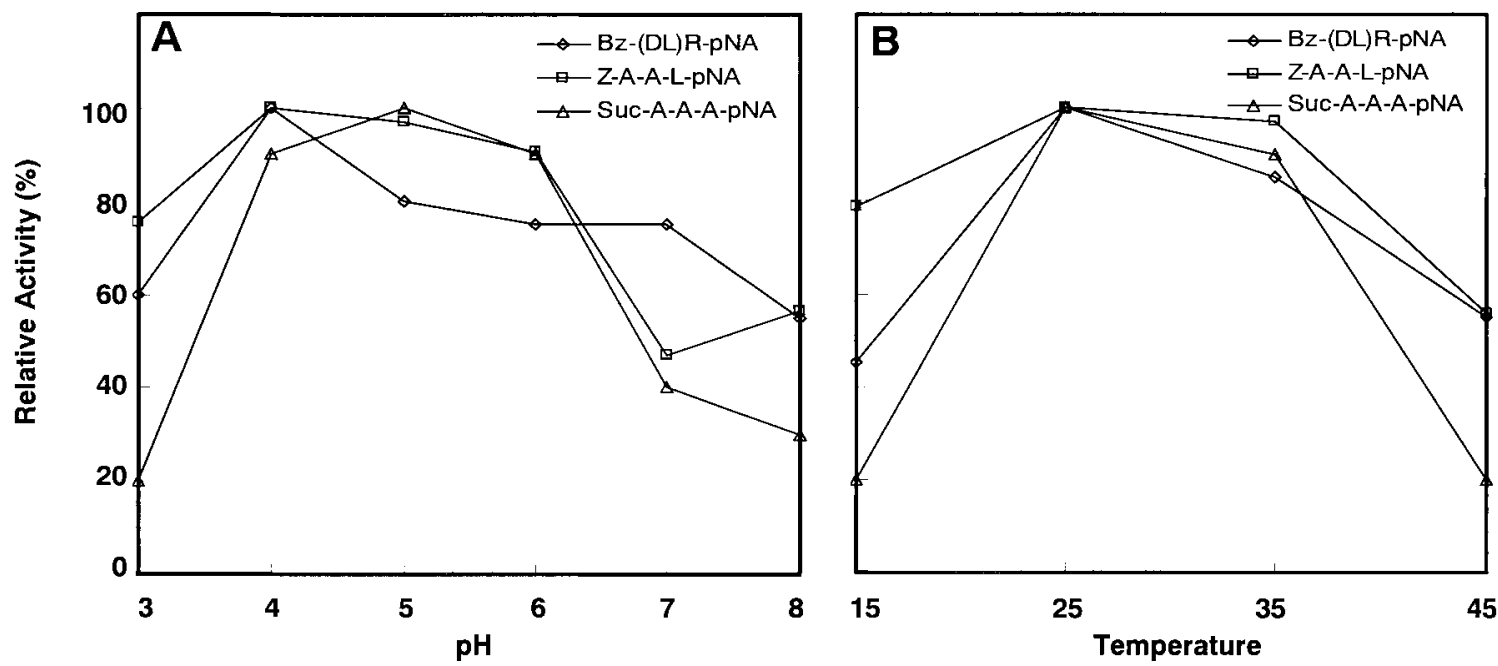

Fig. 1. $\mathrm{pH}$ and temperature dependence of rHISP. (A) rHISP were run in the mixture with the $\mathrm{pH}$ indicated and activities on chromogenic substrates Bz-(DL)-Arg- $p$ NA (Bz-(DL)R- $p$ NA), Z-Ala-Ala-Leu- $p$ NA (Z-A-A-L- $p$ NA) and Suc-Ala-Ala-Ala$p$ NA (Suc-A-A-A-pNA) were determined. (B) The activities of the recombinant enzymes on the substrates described above were tested at deferent temperatures indicated. Results are expressed as a mean percentage enzyme activity relative to the corresponding control value $(100 \%)$.

Table 2. Inhibition of rHISP activity by various proteinase inhibitors

\begin{tabular}{lcccc}
\hline Inhibitor & Concentration $(\mu \mathrm{M})$ & \multicolumn{3}{c}{ Activity inhibited (\% of control) } \\
\cline { 3 - 5 }$($ Specificity) & & Bz-(DL)R- $p$ NA & Z-A-A-L-pNA & Suc-A-A-A-pNA \\
\hline $\begin{array}{l}\text { E-64 } \\
\text { (for all cystaine proteinases) }\end{array}$ & 10 & 82 & 5 & 5 \\
$\begin{array}{l}\text { Antipain } \\
\text { (trypsin-like serine proteinases) }\end{array}$ & 50 & 75 & 65 & 40 \\
$\begin{array}{l}\text { Leupeptin } \\
\text { (most cystaine and trypsin-like serin proteinase) }\end{array}$ & 100 & 0 & 65 & 43 \\
$\begin{array}{l}\text { PepstatinA } \\
\text { (aspartic proteinases) }\end{array}$ & 100 & 63 & 5 & 5 \\
$\begin{array}{l}\text { PMSF } \\
\text { (serine proteinases) }\end{array}$ & 10,000 & 55 & 65 \\
\hline
\end{tabular}

Purified rHISP enzyme was reacted with the chromogenic substrates in the presence of the proteinase inhibitors with the indicated concentration using enzyme assay described in MATERIALS AND METHODS. Inhibitory effect is indicated as percentage of the maximum hydrolytic activity of rHISP for each substrate.

ied group of digestive serine proteinases in haematophagous insects. But in the blood-feeding ticks, only aspartic and cysteine proteinases have been characterized enzymatically $[3,13,14,16]$. In the previous study, we have identified HISP gene from the hard tick $H$. longicornis as a member of the serine proteinase gene family [9]. The deduced amino acid sequence of HISP showed the highest similarity with the midgut serine proteinase of Rhipicephalus appendiculatus (AAC79567) and also showed similarity with mammalian pancreatic elastases. HISP has shown to conserve catalytic triad, His-57, Asp-102 and Ser-195 (chymotrypsinogen numbering), which is indispensable for enzyme activity [4] and there are highly conserved regions among mammalian and arthropod serine proteinases. The endogenous enzymes found to be expressed throughout the development of $H$. longicornis and were localized in the midgut epithelial cells of the ticks [9]. In addition, its expression was found to be up-regulated by the blood-feeding process. Moreover, the recombinant HISP was demonstrated to degrade bovine serum albumin. These results indicate its involvement in the blood digestion within the midgut.

In the present study, rHISP exhibited potent hydrolytic activity on Bz-(DL)-Arg- $p$ NA (substrate for trypsin-like serine proteinase) and Z-Ala-Ala-Leu- $p$ NA (substrate for subtilisin A-like serine proteinase), while it shows reduced activity on Suc-Ala-Ala-Ala- $p$ NA (substrate for elastase), and very little activity was achived with Suc-Arg-Pro-PheHis-Leu-Leu-Val-Tyr-MCA (substrate for renin-like aspartic proteinase) and Pyr-Phe-Leu-pNA (substrate for thiol proteinase). Moreover, the activity of rHISP on the substrates was efficiently inhibited by well known serine proteinase inhibitors such as antipain, leupeptin and PMSF while inhibitors of aspartic and cysteine proteinases had almost no effect on it. These results suggest that rHISP has 
substrate specificity as a typical serine proteinase. In addition, judging from the efficiency of hydrolytic activity on each substrate for serine proteinases, rHISP seems to have similar enzymatic activity with trypsin or subtilisin, although it has higher similarity with mammalian elastases in the sequence analysis. We report for the first time on enzymatic characterization of functional serine proteinase of the hard tick.

Different from blood-sucking insects, blood meal digestion in haematophagous ticks is believed to be a slow intracellular process $[1,2]$ while in the blood-sucking insects it proceeds in the lumen of the intestine. During the first stage of the digestion, the blood meal is being concentrated in the gut lumen and the hemolysis of the red blood cell begins, then in the second stage, component of the blood cells are uptaken into digestive epithelial cells in the tick midgut and intensive digestion starts within lysosomes. The optimum $\mathrm{pH}$ of the enzyme involved in intracellular digestion is thought to be around 3.0 [12], which is suitable to act in acidic environment of lysosomes, and the presense of aspartic and cysteine proteinases proteolytic activities was indicated in the midgut of adult engorged female of $B$. microplus [8]. However, little information is available about the hemolytic enzymes in the first stage of the digestion. The optimum $\mathrm{pH}$ of 5.0 for rHISP is more close to the $\mathrm{pH}$ of the midgut (around $\mathrm{pH}$ 6) rather than lysosomal $\mathrm{pH}$, indicating the probability that rHISP takes part in the hemolysis in the lumen. The presence of putative secretion signal sequence also supports this idea [9].

Generally, hard ticks have drastic environmental changes in its life. In the case of the three host tick H. longicornis, every autumn they drop off and in the next spring reattach to a new host for each life stage, until finally the adult females lay their batch of eggs. During attaching mammalian hosts the temperature of the circumstance is around $35^{\circ} \mathrm{C}$, but after dropping off, it is depending on the ambient temperature. Recently, broad temperature activity profiles were also shown with cysteine endopeptidase purified from eggs of the hard tick B. microplus [15]. Broad preference of HISP for temperature might be related to behavioral features of the hard ticks. In summary, enzymatic characterization of HISP would contribute to better understanding of the mechanisms of blood meal digestion as well as host-tick interactions during a blood-feeding process in the hard ticks.

ACKNOWLEDGEMENTS. This work was supported by the 21st Center of Excellence Program for Scientific Research (to F.K) and Grant-in-aids (N.T., F.K.) from the Ministry of Education, Culture, Sports, Science, and Technology of Japan. This work was supported by a grant from the Program for Promotion of Basic Research Activities for Innovative Biosciences (N.T., F.K.). We would like to thank Ms. Y. Kimura for the excellent technical assistance.

\section{REFERENCES}

1. Akov, S. 1982. Blood digestion in ticks, pp. 197-211. In: Phys- iology of Ticks (Obenchain, F. and Galun, R. eds.), Pergamon Press, Oxford.

2. Coons, L.B., Rosell-Davis, R. and Tarnowski, B.I. 1986. Blood meal digestion in ticks. pp. 248-279. In: Morphology, Physiology and Behavioural Biology of Ticks (Sauer, J.R. and Hair, J.A. eds.), Ellis Harwood/John Wiley, New York.

3. Da Silva Vaz, I., Logullo, C., Sorgine, M., Velloso, F.F., Rosa de Lima, M.F., Gonzales, J.C., Masuda, H., Oliveira, P.L. and Masuda, A. 1998. Immunization of bovines with an aspartic proteinase precursor isolated from Boophilus microplus eggs. Vet. Immunol. Immunopathol. 66: 331-341.

4. Dodson, G. and Wlodawer, A. 1998. Catalytic triads and their relatives. Trends Biochem. Sci. 23: 347-352.

5. Fujisaki, K. 1978. Development of acquired resistance and precipilating antibody in rabbits experimentally infested with females of Haemaphysalis longicornis (Ixodoidea;Ixodidae). Natl. Inst. Anim. Health Q. (Tokyo) 18: 27-38.

6. Fujisaki, K., Kawazu, S. and Kamio, T. 1994. The taxonomy of the bovine Theirelia spp. Parasitol. Today 10: 31-33.

7. Jiang, Q., Hall, M., Noriega, F.G. and Wells, M. 1997. cDNA cloning and pattern of expression of an adult, female-specific chymotrypsin from Aedes aegypti midgut. Insect Biochem. Mol. Biol. 27: 283-289.

8. Mendiola, J., Alonso, M., Marquetti, M.C. and Finlay, C. 1996. Boophilus microplus: Multiple proteolytic activities in the midgut. Exp. Parasitol. 82: 27-33.

9. Miyoshi, T., Tsuji, N., Islam, M.K., Kamio, T. and Fujisaki, K. 2004. Cloning and molecular characterization of a cubilinrelated serine proteinase from the hard tick Haemaphysalis longicornis. Insect Biochem. Mol. Biol. (in press).

10. Netzel-Arnett, S., Hooper, J.D., Szabo, R., Madison, E.L., Quigley, J.P., Bugge, T.H. and Antalis, T.M. 2003. Membrane anchored serine proteases: a rapidly expanding group of cell surface proteolytic enzymes with potential roles in cancer. Cancer Metastasis Rev. 22: 237-258.

11. Rawlings, N.D. and Barrett, A.J. 1994. Families of serine peptidases. Methods Enzymol. 244: 19-61.

12. Reich, C.I. and Zorzopulos, J. 1978. Boophilus microplus: Characterization of larval proteases. Exp. Parasitol. 44: 1-6.

13. Renard, G., Garcia, J.F., Cardoso, F.C., Richter, M.F., Sakanari, J.A., Ozaki, L.S., Termignoni, C. and Masuda, A. 2000. Cloning and functional expression of a Boophilus microplus cathepsin L-like enzyme. Insect Biochem. Mol. Biol. 30: 1017 1026.

14. Renard, G., Lara, F.A., de Cardoso, F.C., Miguens, F.C., Dansa-Petretski, M., Termignoni, C. and Masuda, A. 2002. Expression and immunolocalization of a Boophilus microplus cathepsin L-like enzyme. Insect Mol. Biol. 11: 325-328.

15. Seixas, A., Dos Santos, PC., Velloso, FF., Da Silva Vaz, I. Jr., Masuda, A. and Horn, F. 2003. Termignoni C. A Boophilus microplus vitellin-degrading cysteine endopeptidase. Parasitology 126: 155-163.

16. Sorgine, M.H., Logullo, C., Zingali, R.B., Paiva-Silva, G.O., Juliano, L. and Oliveira, P.L. 2000. A heme-binding aspartic proteinase from the eggs of the hard tick Boophilus microplus. J. Biol. Chem. 275: 28659-28665.

17. Soulsby, E.J.L. 1986. Helminths, Arthropods and Protozoa of Domesticated Animals 7th ed., Blliere Tindall, London.

18. You, M., Xuan, X., Tsuji, N., Kamio, T., Taylor, D., Suzuki, N. and Fujisaki, K. 2003. Identification and molecular characterization of a chitinase from the hard tick Haemaphysalis longicornis. J. Biol. Chem. 278: 8556-8563. 